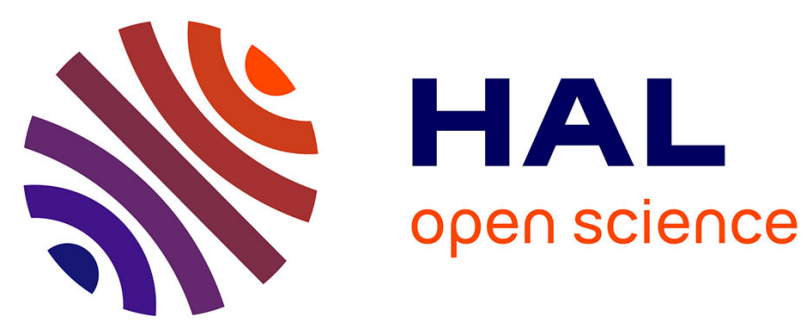

\title{
The endocast of the Late Middle Palaeolithic Manot 1 specimen, Western Galilee, Israel
}

Dominique Grimaud-Hervé, Lou Albessard-Ball, Ariel Pokhojaev, Antoine

Balzeau, Rachel Sarig, Bruce Latimer, Yvonne Mcdermott, Hila May, Israel

Hershkovitz

\section{To cite this version:}

Dominique Grimaud-Hervé, Lou Albessard-Ball, Ariel Pokhojaev, Antoine Balzeau, Rachel Sarig, et al.. The endocast of the Late Middle Palaeolithic Manot 1 specimen, Western Galilee, Israel. Journal of Human Evolution, In press, pp.1-46. 10.1016/j.jhevol.2019.102734 . hal-03006445

\section{HAL Id: hal-03006445 \\ https://hal.science/hal-03006445}

Submitted on 26 Nov 2020

HAL is a multi-disciplinary open access archive for the deposit and dissemination of scientific research documents, whether they are published or not. The documents may come from teaching and research institutions in France or abroad, or from public or private research centers.
L'archive ouverte pluridisciplinaire HAL, est destinée au dépôt et à la diffusion de documents scientifiques de niveau recherche, publiés ou non, émanant des établissements d'enseignement et de recherche français ou étrangers, des laboratoires publics ou privés.

\section{(1)(1) $\$(0)$}

Distributed under a Creative Commons Attribution - NonCommercial - ShareAlikel 4.0 
Title: The endocast of the Late Middle Palaeolithic Manot 1 specimen, Western Galilee, Israel

Dominique Grimaud-Hervé 1, Lou Albessard-Ball 2, Ariel Pokhojaev 3, Antoine Balzeau 4, Rachel Sarig 5, Bruce Latimer 6, Yvonne McDermott 7, Hila May 8, Israel Hershkovitz 9

Affiliations collapse

Affiliations

1UMR 7194 - HNHP, Département Homme et Environnement, Musée de l'Homme, Paris, France. Electronic address: dominique.grimaud-herve@mnhn.fr.

2UMR 7194 - HNHP, Département Homme et Environnement, Musée de l'Homme, Paris, France; PalaeoHub, Department of Archaeology, University of York, UK.

Electronic address: lou.albessard@mnhn.fr.

3Department of Anatomy and Anthropology, Sackler Faculty of Medicine, Tel-Aviv University, Tel Aviv, Israel; Departments of Orthodontics and Oral Biology, The Maurice and Gabriela Goldschleger School of Dental Medicine, Tel-Aviv University, Israel. Electronic address: pokhojaev@gmail.com.

4UMR 7194 - HNHP, Département Homme et Environnement, Musée de l'Homme, Paris, France; Department of African Zoology, Royal Museum for Central Africa, B-3080, Tervuren, Belgium. Electronic address: antoine.balzeau@mnhn.fr.

5Dan David Center for Human Evolution and Biohistory Research, Sackler Faculty of Medicine, Tel-Aviv University, Tel Aviv, Israel; Departments of Orthodontics and Oral Biology, The Maurice and Gabriela Goldschleger School of Dental Medicine, Tel-Aviv University, Israel. Electronic address: rachel.sarig@gmail.com. 
6Department of Orthodontics, School of Dental Medicine, Case Western Reserve University, Cleveland, OH, USA; Department of Anatomy, Case Western Reserve University, Cleveland, OH, USA. Electronic address: bxl14@case.edu.

7Department of Biology, Case Western Reserve University, Cleveland, OH, USA. Electronic address: ypmcdermott@gmail.com.

8Department of Anatomy and Anthropology, Sackler Faculty of Medicine, Tel-Aviv University, Tel Aviv, Israel; Dan David Center for Human Evolution and Biohistory Research, Sackler Faculty of Medicine, Tel-Aviv University, Tel Aviv, Israel. Electronic address: 2hilamay@gmail.com.

9Department of Anatomy and Anthropology, Sackler Faculty of Medicine, Tel-Aviv University, Tel Aviv, Israel; Dan David Center for Human Evolution and Biohistory Research, Sackler Faculty of Medicine, Tel-Aviv University, Tel Aviv, Israel. Electronic address: anatom2@tauex.tau.ac.il.

\footnotetext{
Abstract

Endocasts allow anthropologists to follow changes in the external topography and overall size of the brain during the evolution of hominins. The almost complete calvaria of Manot 1 presents the opportunity to gain insights into the external brain morphology, vascular system, and dimensions of the brain for this late Middle Palaeolithic hominin. Detailed size and shape analyses of the Manot 1 endocast suggest a modern Homo sapiens anatomy, despite the presence of some primitive features on the calvaria. Traits considered to be derived endocranial features for Homo sapiens are present on Manot 1 , including an elongated parietal sagittal chord with an elevation of the superior part of the hemisphere, a large distance between the posterior parts of the frontal lobes, a
} 
considerable development of the parietal reliefs such as the supramarginal lobules, and a slight posterior projection of the occipital lobes. These findings, together with data presented in previous studies dismiss the possibility of a direct Neandertal ancestry for the Manot 1 hominin and confirm its affiliation with modern Homo sapiens. The calvaria has been shown to be more similar to later Upper Palaeolithic Homo sapiens than it is to the earlier Levantine populations of Skhul and Qafzeh. The late Middle Palaeolithic date of Manot 1 provides an opportunity to discuss the recent trends in human cerebral morphology and organization.

Keywords: Manot 1 Cave, Endocast, Human Evolution, Palaeoneurology, Early settlements of Eurasia, Upper Palaeolithic

\section{. Introduction}

Manot is a large karstic cave located in Israel's Western Galilee, about $5 \mathrm{~km}$ east of the Mediterranean shoreline, on the southern slope of a limestone hill, $220 \mathrm{~m}$ above sea level. The cave is situated in a Mediterranean woodland setting with mean annual precipitations of $600-700 \mathrm{~mm}$. The main archaeological record of the cave dates to the Early Upper Palaeolithic period ( 46-33ka), while scattered Middle Palaeolithic artifacts were also found in different locations/areas within the cave (Hershkovitz et al., 2015; Barzilai et al., submitted; Marder et al., 2018). The cave consists of an elongated main hall (80 m long, 10-25 m wide) and two side chambers connected to the hall from the north and the south (Barzilai et al., 2016, submitted). The Manot 1 calvaria was found in one of the side chambers of the cave, resting on a flowstone ledge (Hershkovitz et al., 2015). The crusts on the Manot 1 calvaria was dated by U/Th to a minimum age of 54.7 \pm 5.5 ka (arithmetic mean \pm 2 standard deviations) (Hershkovitz et al., 2015). Because of its geochronological setting, the Manot 1 calvaria is a key fossil in reconstructing the 
evolution of Middle Palaeolithic hominins and their dispersal pattern into Eurasia. The Levant has long been considered an important migratory corridor between Africa and Eurasia. Homo sapiens remains from the Middle and Upper Palaeolithic in this region are rare and morphologically diverse. In its cranial morphology, Manot 1 differs from both the earlier anatomically modern humans (AMH) of Skhul and Qafzeh (Israel) dated between 120-90 ka (Yokoyama et al., 1997), and the later, Upper Palaeolithic fossils of the region (Ohalo II and Nahal Ein Gev I) (Hershkovitz and Arensburg, 2017).

The detailed anatomy and the discrete characters of the skullcap have been described elsewhere (Hershkovitz et al., 2015, 2017) with an estimation of the cranial capacity. Although Manot 1 possesses some primitive traits (e.g., suprainiac fossa), the calvaria is most similar in overall shape and conformation to modern humans (Hershkovitz et al., 2015), and it shows some features most commonly found in Upper Palaeolithic

\section{Europeans.}

Moreover, its general shape deviates from that of the earlier Homo sapiens of the region, such as, Skhul and Qafzeh. These observations led to our conclusion that the group from which the Manot 1 calvaria derived represents a late Out-of-Africa migration event, succeeding earlier settlers that had arrived in the Levant at ca. 90-120 ka (Skhul and Qafzeh), and that the Manot population could have been ancestral to the Upper Palaeolithic populations of Europe (Hershkovitz et al., 2015, 2017).

As the internal surface of the skullcap bears imprints of the vascular network and external brain morphology (e.g., Grimaud-Hervé, 1997, 2004; Holloway et al., 2004; GrimaudHervé and Lordkipanidze, 2010; Balzeau et al., 2013; Bruner et al., 2015, 2018), it can provide important information regarding the taxonomic affinity of the Manot 1 specimen. Endocast morphology provides data regarding species-specific characters as well as intragroup variations. A brief description of the endocast was published in Hershkovitz et al (2015, Supplementary Information). Here, we provide a detailed description of the morphology, organisation and vascularisation of the endocast. We carried out a comparative study of Manot 1 with a large sample of fossil hominins and extant humans. 
Based on the results and on the description of the anatomical characters, we provide a discussion of Manot 1's affinities within the context of the Levant during the Middle and Upper Palaeolithic and of its significance for the understanding of hominin and Homo sapiens cerebral variation through time.

\section{Material and Methods}

The calvaria of the Manot 1 specimen is well preserved and shows no plastic deformation. Endocranially the surviving parts of the calvaria comprise the posterior part of the frontal lobes, the entire surface of the parietal and occipital lobes, a small part of the temporal lobes including the posterior parts of the superior, middle and inferior convolutions, and the superior part of the cerebellar lobes (Figure 1).

A thin layer of calcitic crust covers most of the internal surface, and could not be mechanically removed without irreparably damaging the specimen. The adhering matrix was thus removed virtually in order to create a three-dimensional model of the fossil showing all of the preserved endocranial surfaces. The encephalic and vascular topography is well preserved both on the internal surface of the bone and on the complementary virtual reconstruction of the endocast.

A 3D surface mesh of Manot 1 was segmented and reconstructed from a micro-CT scan

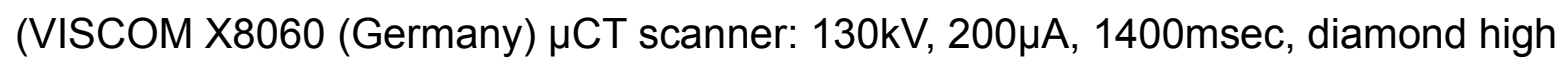
performance transmission target, $0.5 \mathrm{~mm}$ copper filter, spatial resolution $28.2 \mu \mathrm{m}$ ) in the Amira software (v. 6.3). The external surface of this incomplete calvaria was manually deleted to reveal the "positive" model of the endocranial surface which reproduces details of the cortical morphology. Different orientations and lighting directions were used within the MeshLab software to enhance the endocranial features.

\subsection{Comparative material}

The comparative material used for the metrical analyses appears in Table 1.

Comparative data were collected from high-quality physical endocasts and virtual 
models at the collections of the Museum national d'Histoire naturelle and Institut de Paléontologie Humaine, Paris (France), Columbia University, New York (USA), La Sapienza University, Rome (Italy), Institut Royal des Sciences Naturelles, Bruxelles (Belgium) and the Dan David Center for Human Evolution and Biohistory Research, Tel Aviv University (Israel).

The comparative sample comprises 54 fossil hominins and 121 modern humans, all are adult individuals. The sample includes different groups of the genus Homo, such as Homo erectus (s.l.) from Africa and Asia $(n=16)$; Homo neanderthalensis $(n=12)$; African Middle Pleistocene hominins (4) and early Levantine Homo sapiens ( $n=5)$, Anatomically Modern Humans from Europe and the Levant $(n=16)$ and a large sample $(n=121)$ of recent modern humans (both sexes) from various geographical regions (Europe, Pacific area, Africa, Asia and America).

\section{Methods}

\subsection{General description}

The morphological description of the Manot 1 endocranium is based on both the virtual model produced by the micro CT data and on direct observations made on the corresponding internal surface of the original skullcap, used in a complementary manner in order to better appreciate a greater proportion of reliefs and depressions. Special attention was paid to the position and relative expansion of each cerebral lobe, to the degree of expansion of some particular cerebral features (for example frontal or parietal reliefs) and to the vascular patterns including the sinusal imprints and the middle meningeal system (following to the Terminologia Anatomica, 1998).

\subsection{Traditional morphometrics}


Due to the state of preservation of Manot 1, limited linear measurements (Table 2 and Figure 2a) could be carried out on the physical and virtual models of the endocast. They include: the maximal width of the endocast (WME); the maximal width of the biparietal lobes (WBE), and the maximal width taken at the base of both inferior frontal convolutions (WBFE). This last measurement replaces the usual measurement of the maximal width between Broca's areas (WCBE) (Grimaud-Hervé and Lordkipanidze, 2010), as these cerebral pars are unfortunately not preserved in the Manot 1 specimen. Partial heights were measured from the endobregma (HBRE) and endovertex (HGQE) down to the axis representing the maximal length of the hemispheres (LME) (which is estimated on Manot 1). The posterior projection of the occipital lobes (DOcE) was measured as the distance from the most depressed point at the torcular herophili projected perpendicularly to the most posterior point of each hemisphere plane to capture only anterior-posterior variation without a lateral component. The sagittal chords of the parietal $(\mathrm{CPa}=$ between both central fissure and external perpendicular sulci) and the occipital $(\mathrm{COc}=$ between the external left and right perpendicular sulci and the most depressed point of the torcular herophili) cerebral lobes were measured on the virtual model of the endocast (for details see: Grimaud-Hervé and Lordkipanidze, 2010). Unfortunately, the frontal and temporal cerebral lobes are incomplete and their maximum dimensions could not be reliably estimated.

To investigate endocast asymmetry, we compared the specific reliefs of the inferior frontal gyri (preserved Broca's area) and the superior and inferior parietal gyri (supramarginal lobule and angular lobule) between the left and right hemispheres. Univariate analyses were carried out using adjusted z-score (Azs) (Scolan et al., 2012), in which $95 \%$ of the variation of the reference population is included between -1 and +1 . An Azs lower than -1 or higher than +1 is, therefore, outside $95 \%$ 
of the variation of the reference population. This allows the identification of the main differences of Manot relatively to the comparative groups of the sample. To highlight the elongation of the parietal lobe in Homo sapiens, the following index was calculated: parietal lobe sagittal chord X 100 / Occipital sagittal chords (CPa X 100 / COc). The following measurements were used for the Principal Components Analysis : WBFE (and not WBE or WME which are located very close each other and are redundant), HGQE (and not HBRE for the same reason), CPa and DOcE (and not COc redundant with DOcE).

\subsection{Mathematical estimation of the cranial capacity}

In order to complete the precedent estimations of cranial capacity of Manot 1

(Herskhovitz et al., 2015 SI), two mathematical methods using some dimensions (Figure 2b) of the skull are performed (Olivier et al. 1978).

$\mathrm{CC} 1=\left(0.4151^{*} \mathrm{LMC}^{*} \mathrm{WBP}^{*} \mathrm{HGI}^{*} 10^{3}{ }^{3}\right)+342.7$

$C C 2=\left(7.410^{*} \mathrm{LMC}\right)+(11.7 \mathrm{WBP})+\left(5.554^{*} \mathrm{HGI}\right)-2141.8$

LMC $=$ Maximal length of the skull estimated on Manot 1

WBP = Biparietal Width of the skull

$\mathrm{HGI}=$ Height above the line Glabella (estimated) - Inion

\subsection{Shape analysis (landmark-based geometric morphometrics)}

A shape analysis was performed using landmark-based Geometric Morphometrics. The landmarks used in this analysis (Table 3 \& Figure 3) are described in Grimaud-Hervé \& Lordkipanidze (2010). Landmarks which are not present on the Manot 1 endocast were excluded from the study. In order to maximize the number of individuals, only the landmarks digitized on the left hemisphere were considered, as this hemisphere was better preserved on most of the incomplete specimens under consideration. Landmark coordinates were collected on the virtual endocasts of Manot 1, Qafzeh 9 and Nahal 
Oren 16 in the Viewbox software. The position of each landmark was visually checked twice by two of the authors (D.G.H. and L.A.B.), following their initial digitization and adjusted when necessary. The data for the rest of the comparative sample was collected by D.G.H. on endocasts, using a Microscribe.

Landmark coordinates were uploaded in the R environment and a Procrustes superimposition analysis was performed using the gpagen function of the Geomorph package (Adams et al., 2016). Procrustes distances between the aligned individuals were plotted with the plotOutliers function of Geomorph, and the configurations of the outliers were checked individually for errors in landmark placement (e.g. inversions in the order of bilateral landmarks. A Principal Component Analysis (PCA) was then performed on the entire sample (including Manot 1) in order to assess morphological variations in the sample and Manot 1's place relatively to the different groups within the shape space. A between-group PCA was also performed in order to highlight the main differences between the sample's groups. Manot 1 was treated as a group of its own.

\section{Results}

\subsection{Description of the Endocast of Manot 1}

\subsubsection{Overall morphology}

Owing to the well-developed supramarginal gyri in Manot 1, the coronal curvature of the endocast is maximal at this level of the parietal lobes (Figure 1a).

In posterior view (Figure 1b), the endocast presents a pentagonal, dome-shaped outline because the location of the two maximum width measurements (maximal overall width and maximal bi-parietal width) are close to each other and located high on the parietal lobes. The lateral walls of the endocast are parallel and form a strong angulation (corresponding to the expansion of supramarginal gyri) with the superior part of the brain. 
This posterior outline is slightly depressed at the level of the intraparietal sulcus, and at its apex, because of the interhemispheric sulcus, covered by the superior longitudinal sinus. The ovoid shaped occipital lobes are fully preserved. In lateral view, the two occipital lobes are situated in anterior position, below the parietal lobes.

The sagittal profile (Figure 1c, d) has a slight curvature in the frontal region, a higher curvature in the parietal region followed by a slight but observable parieto-occipital flattening and a very high curvature in the occipital region.

In superior view (figure 1e), the left and right frontal and parietal lobes converge slightly to the front, while the posterior parts of these lobes angle acutely, which gives the endocast of Manot 1 an ovoid shape. The endocast exhibits a slight right occipital projecting posteriorly (petalia according Holloway and de Lacoste. 1982), left and right hemispheres are equally wider. On each side of the inter-hemispheric sulcus, small Pacchionian granulations are observed on the endocranial surface.

\subsubsection{Sulcal and gyral imprints of Manot 1 (Figure 4)}

On both hemispheres, the posterior portions of the three frontal convolutions are preserved. The boundaries of these gyri are distinguishable in the form of numerous and clearly delineated eminences, all the way to the imprint of the coronal suture. As usually observed in hominin endocasts, the width of both superior frontal gyri increases in the antero-posterior direction.

Unfortunately, much of the inferior frontal convolutions are not preserved. Only the important expansion of the very superior part of these gyri survive, offering an idea of what the bulging of the Broca's area would have been. From the preserved portion and by comparison with other hominins endocast, it appears that this relief was probably strongly developed on Manot 1 . The relief of the pars opercularis of the left inferior 
frontal gyri is well marked and delineated anteriorly by the vertical depression of the lateral sulcus.

While the central and precentral sulci are difficult to locate with precision on both hemispheres, the depression of the central sulci can be detected near the interhemispheric fissure, between the reliefs of the two Pacchionian granulations. It is therefore possible to estimate where these sulci intersect with the interhemispheric fissure and thus to know how far the frontal lobes extend posteriorly. The precentral sulci are observable as a slight depression situated between the central sulcus and the imprint of the coronal suture. The postcentral sulci are more easily located, lying immediately anterior to the well-developed contours of the supramarginal gyrus of the left and right inferior parietal gyri. These limits allow to estimate the widths of these two frontal and parietal ascending gyri (ca. $9 \mathrm{~mm}$ ). The swellings of both superior parietal gyri are notable and strongly convex and their width decreases antero-posteriorly (from 31 to $24 \mathrm{~mm}$ ). They are separated from the inferior parietal gyri by large and shallow depressions, corresponding to the intraparietal sulci. This depression is more pronounced on the right hemisphere. All the reliefs of the inferior parietal gyri are well delineated. The supramarginal gyri are especially developed and strongly marked. They are round in shape and clearly demarcated at their margins. This allows to precisely locate the position of the post central sulcus anteriorly to the supramarginal gyri. The relief of the adjacent base of the inferior parietal gyrus is well defined. Posteriorly, a shallow depression corresponding to the intermediate sulcus separates the supramarginal gyrus from the angular lobule.

The lateral sulcus is deeply imprinted on both hemispheres. Its course is nearly straight, following the successive rounded eminences constituting the superior temporal gyri. Its general orientation is slightly oblique, and its extremity rests below the base of the relief 
of the supramarginal gyrus, which is very well marked. The posterior extremities of the temporal gyri constitute successive, well defined, and clearly delineated eminences up to the junction with the parietal and occipital lobes on both hemispheres.

The pre-occipital notches form clear depressions at the junction between the parietotemporal and occipital lobes. They are located above the right and left transverse sinuses. Meynert's pre-occipital sulci and the external perpendicular sulci are also detectable anteriorly to the imprint of the lambdoidal sutures, although they are partially covered by calcitic matrix.

A large space corresponding to the location of the superior longitudinal sinus separates the two occipital lobes, which are situated below the parietal lobes. On both hemispheres, the limits of the superior and medial occipital gyri are not easily discernible whereas the inferior gyrus is more clearly delineated, particularly on the right lobe.

The cerebellar lobes are only partially preserved, represented by the superior part on the right lobe and half of the left lobe. In lateral view, they seem to be located anteriorly, in equal parts below the temporal and occipital lobes. The shape of the cerebellar lobes is oval. They are separated by the deep and narrow interhemispheric sulcus. The circumferential sulci that divide the cerebellar lobes into superior and inferior portions are apparent on both sides.

\subsubsection{Vascular and sinusal imprints}

Two Pacchionian granulations are seen on both sides of the interhemispheric fissure

(Figure 1e). The larger of the two is located at the level of the ascending frontal 
convolution of the left hemisphere, and a smaller one is situated at the top of the ascending parietal convolution of the right hemisphere.

\section{$\underline{\text { Sinus }}$}

In Manot 1, the superior longitudinal sinus is faintly apparent between the parietal lobes (Figures 1a, 1e) and its diameter increases antero-posteriorly. It disappears at the anterior part of the occipital lobes. Posteriorly it branches into the left and right transverse sinuses with the left being slightly higher than the right (Figure 4c), this feature is perhaps an argument (Grimaud-Hervé, 2004) to decide that the superior longitudinal sinus deviates posteriorly to the left transverse sinus. This is not in agreement with Holloway (in Hershkovitz et al. 2015) who wrote "the major flow is to the right side". Concerning these opposite opinions, it is more cautious to conclude that the connections of the ascending parts of the transverse to the superior longitudinal sinus are unclear and that it is impossible to argue with certainty where and how they deviate from the superior longitudinal sinus.

The diameter of the right sinus is constant and large $(5 \mathrm{~mm})$ and its course clearly demarcated. The left transverse sinus is embedded and thus less obvious beneath the inferior occipital gyrus. The transverse sinuses drain laterally into the sigmoid sinuses preserved only at their uppermost part.

\section{Middle meningeal system}

On the left hemisphere (Figures 1d, 4a), the anterior ramus divides into two branches on the frontal surface and is more developed than the posterior ramus. The anterior bregmatic branch runs vertically upwards along the imprint of the coronal suture. The posterior obelic branch has a short vertical anterior vessel, which runs obliquely posteriorly and upwards. It divides at the base of the supramarginal gyrus into two major 
ramifications, covering the entire supramarginal gyrus surface. The posterior lambdatic branch is poorly defined.

Vascular imprints on the right hemisphere (Figures 1c, 4b) are more numerous and more clearly marked. The anterior meningeal ramus, as on the left hemisphere, is more developed than the posterior ramus. It has a frontal branch that runs anterior to the coronal suture and a bregmatic branch, running posterior to the coronal suture (this blood vessel is located on the surface corresponding to the superior extremities of the inferior and medial frontal gyri). The anterior bregmatic branch runs vertically and divides into two major ramifications, a short anterior branch and a long posterior branch. The posterior division is obliquely oriented and runs along the ascending parietal gyrus, reaching the midsagittal area. At its uppermost parts, a few ramifications branch out from its posterior aspect. The anterior obelic branch follows the base of the inferior parietal convolution. It divides into two unequal branches, a long anterior one, which is less marked, and a posterior one with numerous ramifications emerging from the superior part of the inferior parietal gyrus. The superior extremities of the two vascular branches of the anterior ramus are straight and reach the surface of the superior parietal gyrus where they join together, constituting several anastomoses in this upper parietal region. It is more developed than the posterior lambdatic ramus, which is also divided into two major branches, a long parietal branch that gives a short anterior ramification and an occipital branch, both running all the way to the midsagittal area. In superior view, a dense network of anastomoses is present at the superior aspect of the right hemisphere.

On both hemispheres of the Manot 1 endocast, the anterior ramus of the middle meningeal system (MMS) covers a large encephalic area comprised between the posterior end of the frontal lobes and the posterior part of supramarginal lobules. It is 
much more developed than the posterior ramus, which covers the angular gyrus and reaches the superior parietal gyrus.

To conclude, the major characteristics of the middle meningeal system in Manot 1 are: a notable difference in pattern and complexity between the right and left hemispheres; a vascular network which is more developed on the right hemisphere; an indisputable predominance of the anterior ramus and its numerous anastomoses compared to the posterior rami on both sides; the oblique orientation of the middle meningeal vessels.

\subsection{Comparative descriptive analysis}

\subsubsection{Overall morphology}

The pentagonal dome-shaped outline observed in Manot 1 in posterior view is common to $\mathrm{AMH}$ and extant humans sample. The maximal width of the endocast is located close to the maximal biparietal width on Manot 1, whereas in earlier hominins from Africa and the Levant, the maximal width is located lower than the maximal biparietal width. The lateral walls of the endocast of the Manot 1are slightly oblique, convergent upwards to the top of the supramarginal relief and then regularly convex. They are strongly convergent upwards on Homo erectus, where the parietal reliefs are not prominent. On Neandertals, the lower and posterior position of the relief of the supramarginal gyri gives a circular coronal outline, as observed on the cranium.

In Manot 1, like in the other Levantine $\mathrm{AMH}$, extant humans and Neandertals, the occipital lobes are located under and not as an extension of the parietal lobes as observed on earlier Homo erectus.

The cerebellar lobes in Manot 1 are mostly located under the temporal lobes, a small fraction of them is situated below the occipital lobes, indicating an anterior positioning of 
the cerebellum. This location of the cerebellum is shared among all the Homo sapiens specimens, modern and early alike. They are situated in equal parts under temporal and occipital lobes in Homo erectus, showing a posterior position of the cerebellum in this earlier species.

\subsubsection{Sulcal and gyral imprints}

The cerebral topography of the preserved Manot 1 calvaria is well delineated, and its features align the fossil most closely with the anatomically modern humans $(A M H)$ and extant humans. The lateral sulcus is narrow and deeply imprinted and its course is linear and horizontal. This condition is seen in all the Upper Palaeolithic specimens as well as extant humans. In the Levantine specimens from Qafzeh $(6,9)$ and Skhul (IV), the orientation is similar but the depression is more shallow, and the frontal and temporal lobes border a close Sylvian valley. On Homo neanderthalensis specimens, the lateral sulcus is clearly printed with an orientation slightly straightened up at its superior extremity, which is not the case in Homo erectus (s.l.) where the depression is superficial and obliquely oriented all along its course.

Although the temporal pole and the inferior part of the frontal lobe are missing in Manot 1, the configuration of the lateral sulcus suggests a narrow Sylvian opening, similar to that seen in Qafzeh, Skhul, Mladeč 1, Cro-Magnon 1, 3, Predmost 3, Predmost 10, Cavillon 1, Pataud 1, Ohalo 2, Nahal Oren 16 and the extant human sample. The opening between these two lobes is wider on Neandertals, as they are largely separated on Homo erectus (s.I.).

The depression of the intraparietal sulcus is less defined in Qafzeh 3, 9 and in Skhul V. This feature is however well impressed in Jebel Irhoud 1 and 2, Qafzeh 6 and Manot 1, and it laterally defines large and convex superior parietal gyri, with the width decreasing antero-posteriorly on all AMH fossil endocasts and extant humans. The well-marked 
reliefs of the supramarginal gyrus from the angular lobule in Manot 1 are separated by an intermediate sulcus as on most other modern humans. The supramarginal gyrus in modern humans and AMH is located in the upper part of the endocast and is rounded in shape. The bulging is extremely protuberant on Manot 1, Mladeč 1, Cro-Magnon 1, 2, 3, Predmost 10, 4, 9, Pataud 1, Dolní Věstonice1, 2, Ohalo 2, Nahal Oren 16 and Qafzeh 6 in decreasing order. This rounded structure is moderately accentuated on Qafzeh 3 and 9, Predmost 3 and Brno 3. In the African Middle Pleistocene hominins Jebel Irhoud 1 and 2 (Grimaud-Hervé, 2005), the supramarginal gyrus is located lower and is slightly oval in shape, as it is rounded and in upper position on Kabwe and Laetolil H18. On theNeandertal sample, the supramarginal gyrus is located in a lower and more posterior position and is oval in shape. This relief is not distinguishable on Homo erectus.

The surface of the angular lobule is equivalent or slightly smaller than the supramarginal gyrus on all the hominins of the studied sample, with a less clearly delimited and less developed relief.

On the preserved part of the temporal lobes in Manot 1, well delineated and rounded convexities are located between the temporal sulci similar to those seen in Pataud 1, Cro Magnon 1, Nahal Oren 16, Brno 3 (preserved on the left side), Predmost 3 (left side preserved), Predmost 9 and 10, Cavillon 1 (preserved on the right). The temporal topography is less marked on Qafzeh 9 and Ohalo 2 (on the left, right side not preserved). These temporal regions are not,or poorly, preserved on Qafzeh 3, 6, Skhul V, Mladeč 1, Dolní Věstonice1, Cro-Magnon 2, 3, and Predmost 4. Concerning African Middle Pleistocene hominins, the temporal topography is well marked on Jebel Irhoud 2 but not on Jebel Irhoud 1, as Kabwe and LH18. On Neandertals, the temporal reliefs are well developed and separated by deep temporal sulci. It is not the case on Homo erectus where the temporal cerebral surface is smooth and sulci depressions 
sometimes difficult to localize. This increasing of temporal reliefs separated by deeper sulci is probably in relation with the increasing of the brain volume.

\subsubsection{Sinusal and vascular imprints}

\section{$\underline{\text { Sinus }}$}

Manot 1 presents an unclear sinusal organization of the torcular herophili, but the higher position of the left transverse sinus is perhaps an argument to conclude that the superior longitudinal sinus merges into the left transverse sinus. The superior longitudinal sinus deviates to the left transverse sinus on Nahal Oren 16. This configuration is less common than deviations to the right transverse sinus, which are observed on Qafzeh 3, 6, Skhul V, Mladeč 1, Dolní Věstonice 2, Cro-Magnon 1 and 3, Predmost 3, 4, 9, and 10, Brno 2 and 3, Cavillon 1, Pataud 1, Ohalo 2 and Nahal Oren 24 , in the majority (80\%) of extant humans and $85 \%$ of Homo erectus and Homo neanderthalensis (Grimaud-Hervé, 1997, 2004).

\section{Middle meningeal system}

As in all Upper Pleistocene Homo sapiens, Manot 1 shows a developed middle meningeal pattern, with a predominant anterior ramus dividing into bregmatic and obelic meningeal branches. The anterior ramus is more developed than the posterior one, which is especially reduced in all AMH. The general orientation of this vascular pattern in Manot 1 is oblique, as is the case for most Homo sapiens. In earlier hominins, the branches are more vertically oriented (Saban, 1984; Grimaud-Hervé, 1997). The anterior ramus of the middle meningeal pattern in Manot 1 extends from the posterior parts of the frontal gyri to the posterior part of the supramarginal gyri, similar to the condition seen in Qafzeh 3, 6, 9, Cro-Magnon 1, Nahal Oren 16, Skhul V, Predmost 4 and Pataud 1. In contrast, this ramus runs more posteriorly, reaching the angular 
lobule in Predmost 3, 9, Cro-Magnon 3, Brno 3, Dolní Věstonice1, Nahal Oren 24, on the right hemisphere of Predmost 10 and Dolní Věstonice2, and on the left hemisphere of Skhul V, Qafzeh 6, Predmost 4, Pataud 1 and Cavillon 1. In Manot 1. As, in most Homo sapiens, the bregmatic and obelic branches constitute the anterior ramus of the middle meningeal system. In some specimens, however, the obelic branch has a double origin, from both the bregmatic and lambdatic branches (e.g.Qafzeh 9, Predmost 3, CroMagnon 1, Ohalo 2, Nahal Oren 16, on the right hemisphere of Predmost 4, and on the left in Skhul V, Dolní Vestonice 1, 2, Pataud 1 and Ohalo 2.

It seems that the increase in the complexity of the branching pattern of the anterior ramus of the middle meningeal system throughout human evolution is associated with the general reduction in the complexity of the branching pattern of the posterior ramus. Compared to the relatively simple pattern seen in early hominins, modern humans present an elaborate, dense grid of ramifications, covering the entire encephalic surface.

This system differs from that seen in Homo neanderthalensis where the middle meningeal system is reduced and simplified (Grimaud-Hervé, 2004).

This enhanced complexity in the ramifications' crisscrossing pattern is a modern feature observed in Homo sapiens, which does not seem related to the cranial capacity as shown the reduced meningeal system associated to high endocranial volume observed on Homo neanderthalensis.

\subsection{Metrical analysis}

\subsubsection{Morphometric description}


Metrics are presented as means for the respective groups (Table 1) unless otherwise noted in Table 4. Of course, we must be cautions in our interpretation of the metrical comparison between a single individual and sample means.

The maximum width of the endocast $(\mathrm{WME}=127 \mathrm{~mm})$ of Manot 1 is smaller compared to the sample means of early Homo sapiens from the Levant $(137.5 \mathrm{~mm})$ and Middle Pleistocene Homo from Africa (133.3 mm), AMH (136.3 mm), extant humans (136.3 $\mathrm{mm}$ ) and Neandertals $(138.9 \mathrm{~mm})$. This measurement is, however, greater than that of Homo erectus (123.6 mm). For this transversal width, it is outside (smaller) of the variations of Homo neanderthalensis and early Levantine Homo sapiens. With nearly same value, the maximum width between the supramarginal gyri of Manot 1 is larger than in the Homo erectus sample and in the ranges of variations of all the others groups.

The projected hemispheric heights $(\mathrm{HGQE}=70 \mathrm{~mm}$; HBRE $=65 \mathrm{~mm})$ of the Manot 1 endocast are greater than in Homo erectus (58.9 and $55.9 \mathrm{~mm}$ ) and Middle Pleistocene Homo from Africa ( 56.5 and $52 \mathrm{~mm}$ ), falling outside of their limits of variation. Manot 1 is in the range of variations of Neandertals (66.8 and $61.3 \mathrm{~mm}$ ), early Levantine Homo sapiens (70 and $61.2 \mathrm{~mm}), \mathrm{AMH}(78$ and $68.8 \mathrm{~mm})$ and extant humans (66.8 and 59 $\mathrm{mm})$.

The sagittal chord length of the parietal lobes $(\mathrm{CPa})$ in Manot 1 is $78 \mathrm{~mm}$, close to the early Levantine Homo sapiens, AMH and extant humans values. It is much greater and outside of the range of variation of African Middle Pleistocene hominins $(61.5 \mathrm{~mm})$, Homo neanderthalensis $(58.3 \mathrm{~mm})$, and particularly Homo erectus $(47.2 \mathrm{~mm}$.

The occipital lobes in Manot 1 are less projected $(\mathrm{DOcE}=16 \mathrm{~mm}$ ) than in Neandertals (19.5mm), similar to $\mathrm{AMH}$ (16.3 mm), and more projected than Homo erectus (11.5 $\mathrm{mm}$ ), African Middle Pleistocene hominins (14.3 mm), early Levantine Homo sapiens 
$(14 \mathrm{~mm})$; they are considerably more projected than in extant humans $(10.5 \mathrm{~mm})$.

Manot 1 falls inside the range of variation of all the hominin groups considered.

The adjusted z-scores (Azs,) show that Manot 1 falls, in all variables studied, within the range of variation of all Homo sapiens groups, except for cranial capacity when ,compared to the Levantine Homo sapiens sample (Table 4). The specimen is outside the Neandertal range for CPa (2.46) and of the Homo erectus range for $\mathrm{CPa}$ (6.18) and WBE (1.07). The Azs scores when compared with African middle Pleistocene hominins are very high for partial eights (HGQE and HBRE) and the parietal cord. Those features are related to the typical anatomy of Homo sapiens relatively to all other hominin species. 4.2.2. Cranial capacity

Cranial capacity was originally estimated to be around $1100 \mathrm{ml}$ (Hershkovitz et al 2015.S.I.) by averaging the results obtained by two different complementary methods (regressions based on endocranial measurements; and water displacement using a manually reconstructed endocast of Manot 1). The results obtained with each method range from $1010 \mathrm{ml}$ for the water displacement method to $1194.6 \mathrm{ml}$ for the higher regression estimate.

In this study, with the purpose to confirm or not the previously obtained estimation, two mathematical methods (Olivier et al. 1975, 1978) are performed from linear measurements of the skull :

$\mathrm{CC} 1=\left(0.4151 * \mathrm{LMC}^{*} \mathrm{WBP} * \mathrm{HGI}^{*} 10{ }^{3}\right)+342.7$

$\mathrm{CC} 2=(7.410 * \mathrm{LMC})+(11.7 \mathrm{WBP})+(5.554 * \mathrm{HGI})-2141.8$

The measurements of the skull of Manot 1 are:

$\mathrm{LMC}=$ Estimated Maximal length of the skull $=$ between $177 \mathrm{~mm}$

WBP $=$ Width Biparietal of the skull $=135 \mathrm{~mm}$

HGI $=$ Height above the line (estimated) Glabella - Inion $=87 \mathrm{~mm}$

Our results are higher than Holloway's previous estimation (Hershkovitz et al, 2015, S.I.) with $\mathrm{CC} 1=1205 \mathrm{ml}$

$\underline{\mathrm{CC} 2}=1232 \mathrm{ml}$. 
With an average of $1218.5 \mathrm{ml}$, the cranial capacity of Manot 1 specimen is more elevated and outside of the variation range of the Homo erectus, it is too small and outside of the variation range of earlier Levantine Homo sapiens and AMH. It falls within the lower variation of Homo neanderthalensis, African Middle Pleistocene hominins and extant humans sample of this study and within the known variation of Homo sapiens (Beals et al. 1984).

\subsubsection{Multivariate analysis}

\section{Principal component analysis}

The results of a principal components analysis, based on four variables (WBFE, HGQE, CPa, DOcE), appear in Figures 5 and 6.

When PC1 and PC2 are plotted, explaining $78.8 \%$ of the total variance, Homo erectus are separated from Homo sapiens on PC1. Neandertals and African Middle Pleistocene hominins overlapping with the variation range of $\mathrm{AMH}$ and are separated from eachother along PC2 (Figure 5). No individualization of species appears along the PC2 axis, and the very large variation of the extant human sample covers those from earlier Homo. Manot 1 falls within the modern human range and outside of the ranges of other groups. When PC1 and PC3 are plotted (56\% of total variance), AMH and early Levantine Homo sapiens are separated along PC3 (Figure 6). Manot 1 falls close to the $\mathrm{AMH}$ specimens' variation, within the range of extant humans and slightly away from the earlier Levantine Homo sapiens group.

Multivariate analysis (geometric morphometric)

The sample shows large amounts of variation, the first 10 PCs explain $85 \%$ of total sample variation, and each PC represents only a small amount of the total variation (PC1: 15.6\%, PC2: 14.9\%). (Figure 7) 
PC1 (15.6\% of total sample variation) separates between Homo erectus and Homo sapiens. The other groups (Neandertals, African Middle Pleistocene hominins and AMH) are located between these two groups. As illustrated by the shape deformation graphs, PC1 relates to the location of the maximal endocranial width (Endo-Euryon): at the positive end of the axis are specimens where the endocranial maximal width (EndoEuryon) is positioned high on the endocast (blue), whereas on the negative end are the specimens where it is located low on the endocast (red). Manot 1 is located close to the positive end. Compared with endocasts at the negative end of the axis, endocasts at the positive end of the axis are globular, and feature a center of the supramarginal gyrus which is located more anteriorly, a higher and more anterior maximum width, and more anterior position of the cerebellar lobes relative to the occipital pole, accompanied by a slight posterior and downward shift of the point marking the demarcation between the cerebellar and temporal lobes (landmark 6).

PC2 (14.9\%) does not separate between the different hominin groups. The morphological variations represented by this axis relate to the relative expansion of the frontal and parietal lobes, to the projection of the occipital lobes, to the position of the maximum width and between the supramarginal gyri. These variations seem to represent intraspecific variations rather than interspecific diversity. It is likely that the first two PCs fail to better separate between the two hominin groups because of the incompleteness of the data, as only the parts of the endocast preserved in the Manot 1 specimen were included in the analysis. Manot 1's scores for these two principal components places it within the extant human variation and close to the $\mathrm{AMH}$.

The association between PC1 (15.6\%) and PC3 (10\%) provides better discrimination between the hominin groups. In particular, the AMH group is more closely associated to the extant humans sample, and better differentiated from the Neandertals. On the PC1 
vs. PC3 scatterplot, Manot 1 falls within the extant human hull, away from the Neandertal variation, and close to the AMH hull. The African Middle Pleistocene hominins group falls at the margins of the $\mathrm{AMH}$ and outside of the present-day variation. It is worth noting that the AMH group is represented here by only six individuals and the Neandertals by five, so that each group cannot be considered to represent the true variability of the species it represents. In sum, our shape analysis shows that the form of Manot 1's endocast most resembles that of the extant humans and AMH groups.

\section{Between-group PCA}

The first axis of the between-group PCA (56.7\% of inter-group variation) mostly discriminates the extant human group (positive end of the axis) from the Upper $\underline{\text { Palaeolithic / early Levantine AMH groups (intermediate position) and the Homo erectus }}$ sensu lato / Middle Pleistocene African hominins / Neandertals groups at the negative end of the axis. Manot 1 is closest to the extant human / Upper Palaeolithic European and Levantine variation range. The main direction of variation includes a more vertical orientation of the frontal lobes, a relative lengthening of the parietal sagittal chord, a reduction in occipital projection, and widened parietal lobes in extant humans compared to the other groups. The second axis (15.5\%) allows to visualize differences between $\underline{\text { the Homo erectus s.l. and Neandertal groups (albeit with some overlap in the ranges of }}$ variation), and the Upper Palaeolithic / early Levantine specimens. Manot 1 falls closest to the Upper Palaeolithic group on this axis. Main differences between the negative and positive ends of the axis include an upward shift of the maximum width of the endocast and a reduction in the posterior projection of the occipital lobe. 


\section{Endocranial asymmetries of Manot 1}

The internal surface of the bone is equally well preserved on both sides of the calvaria, suggesting that any asymmetries in the definition of cortical features, vascularization and hemispherical surface reflects biological asymmetries rather than differential preservation.

\subsubsection{Sinus}

As previously noted, the organization of the torcular herophili observed on Manot 1 is unclear, but the hypothesis of a deviation to the left transverse sinus is favored. According to Galaburda (1995), the deviation of the superior longitudinal sinus to the left transverse sinus is more often noted in left-handed individuals. This configuration is less common than deviations to the right transverse sinus, which usually occur in righthanded individuals in association with a left occipital petalia (Smith, 1907). On these individuals, the markings of the right transverse sinus are larger and located in a higher position than the imprints of the left lateral sinus. This could be an argument for the left deviation of the longitudinal superior sinus suggested for Manot 1 in section 4.1.3 and 4.2.3. This sinusal configuration is usually associated with a right occipital protrusion (or petalia), which is the case in Manot 1, where a slight projection of the right occipital lobe is observed.

\subsubsection{The middle meningeal pattern}

The middle meningeal pattern of Manot 1 is complex and well developed, with numerous and long ramifications, especially on the right hemisphere. This vascular network covers the entire cerebral surface of the right parietal lobe. The middle meningeal system is more developed on the right hemisphere on Dolní Vestonicě 1 , Cro-Magnon 1, 3, Predmost 4; more developed on the left hemisphere on Skhul V and 
Dolní Věstonice 2; and equally developed on Predmost 3, 9, 10, Brno 3 and Pataud 1. So, in extant humans, as in early hominins as Homo erectus, Middle Pleistocene hominins and Homo neanderthalensis (Grimaud-Hervé, 1997, 2004), there appears to be no clear preference for a more developed middle meningeal system to one side over the other.

\subsubsection{Hemispheric length and width}

Asymmetry in frontal lobe protrusion could not be evaluated in Manot 1, because much of this lobe is not preserved. Occipital lobe projection is slightly more important on the right hemisphere.

Studies of fossil hominins and extant humans (Smith, 1907, 1908, 1925; Holloway and De La Coste-Lareymondie, 1982; Grimaud-Hervé, 1997, 2004; LeMay, 1999; Copes and Holloway, 2004; Holloway et al., 2004; Balzeau et al., 2012) suggest that the caudal portion of the left hemisphere protrudes more posteriorly than the right in approximately $70 \%$ of specimens. This asymmetrical configuration of the brain (i.e., forward protrusion of the right frontal lobe and posterior protrusion of the left occipital lobe) is more commonly found in right-handed individuals. This endocranial asymmetry pattern is observed in Qafzeh 3, Cro-Magnon 1, 3, Predmost 3, 4, 9, 10, Cavillon 1, Dolní Věstonice2, Mladeč 1, Pataud 1 (Grimaud-Hervé 1997), and in 44\% of the modern humans of our sample. In most of these specimens, the more protruding lobe is also the wider lobe of the two. Some exceptions, however, exist such as Brno 3 (Grimaud-Hervé 1997), which exhibits strong left frontal and right occipital petalia, usually associated with left-handedness. The left and right parietal lobes are equally wide in Qafzeh 9, Skhul V and Nahal Oren. This pattern is observed in $15 \%$ of extant humans (Balzeau et al., 2012). A leftward projection of both frontal and occipital lobes is observed in $29 \%$ of extant humans. Among modern humans (and in great apes), a rightward frontal petalia 
occurs in $59 \%$ of cases, and a leftward petalia in $41 \%$ (Balzeau et al. 2012). In humans, leftward occipital asymmetries occur at a rate of $73 \%$ and rightward ones occur in $27 \%$ of cases (LeMay, 1999; Balzeau et al., 2012)

In Manot 1, the transversal widths of the frontal lobes, measured at the level of the preserved superior part of the Broca's areas, are equal. The parietal lobes, measured at the level of the supramarginal gyri, are also equal in width. In fossil hominins $(n=54)$ and extant humans ( $n=121)$, no asymmetrical trend for the parietal widths could be noted.

To sum up, the left and right hemispheres of Manot 1 are equally wide, the endocast exhibits a slight posterior projection of the right occipital lobe relative to the left (petalia according to Holloway and de Lacoste. 1982), which could perhaps be related with a righthandedness (Smith, 1907, 1908, 1925; Holloway and De La Coste-Lareymondie, 1982; LeMay, 1999; Copes and Holloway, 2004). This cerebral asymmetry, usually associated to a left deviation of the superior longitudinal sinus to the transverse one, could argue for this configuration in Manot 1 where this sinusal feature is not clearly observed.

\subsubsection{Cortical imprints}

The first and second parietal convolutions, in Manot 1 are clearly imprinted on both hemispheres without any noticeable difference in the pattern between sides. However, their borders appear to be more distinct on the right parietal lobe. The rounded bulging of the supramarginal gyrus is more developed on the left hemisphere in Predmost 3, Brno 3, Cro-Magnon 3 and Dolní Věstonice 2, and in $63 \%$ of modern humans. In contrast, in Predmost 10 , and in $37 \%$ of extant humans it is the right parietal lobe that appears dominant. The relief of the angular lobule is similar on both of the hemispheres of Manot 1 and Predmost 9, whereas it is more clearly visible on the right parietal lobe on Predmost 4 and 10 and on the left hemisphere on Predmost 3, Brno 3, Cro-Magnon 1 
and 3. According to Bruner (2016), sulci and gyri are more defined and visible on the "non-dominant" hemispheric area, that is, on the side showing a smaller volume. This hemispheric specialization, a major feature of the human brain, is associated with lateralized behaviours observed in the archaeological record, such as handedness (Stout et al., 2008, 2015). It is not observed on the Manot 1 specimen. 


\section{Discussion and Conclusions}

The endocast of Manot 1 shows the full suite of anatomically modern Homo sapiens features, both in terms of general morphology and organization and in terms of cortical detail. These features include a pentagonal contour in posterior view; a longitudinally and transversally developed parietal lobe; oval occipital lobes positioned under the parietal; a deep, narrow and nearly horizontal lateral sulcus; a bulging supramarginal gyrus; and a well-developed middle meningeal network with a predominant anterior ramus and an oblique orientation. A trend towards an expansion of the cerebellar lobes relative to the occipital lobes has been documented in extant humans compared to $\mathrm{AMH}$ (Cabestrero-Rincon 2018, see also Weaver 2005). Unfortunately, the cerebellar lobes of Manot 1 are incompletely preserved, which prevents us from assessing with certainty how it fits within this pattern, but according to Hershkovitz et al. (2015 SI), the position of the transverse sinus indicates that the cerebellum occupies less of the occipital bone than in recent Homo sapiens. This would therefore align it with AMH specimens. The main interest of Manot 1's partial endocast is that it documents an example of cerebral shape and organization for a group of Homo sapiens, which is as yet mostly unknown. Early populations of anatomically modern Homo sapiens are present in the Levant around 120-90 kya, following which there is a hiatus in the human remains record, before a morphologically distinct population appears in the Upper Palaeolithic. The late Middle Palaeolithic date for this fossil places it as part of a group which is anterior - and potentially ancestral to -the first Homo sapiens of Central and Western Europe. This would reinforce the hypothesis that the Levant formed a corridor between Africa and Eurasia and played an important role in one or more Out-of-Africa events for this species. 
The final estimation of the endocranial volume is $1100 \mathrm{ml}$, which is in or close to the lower range of variation for Homo sapiens and for Neandertals (Grimaud-Hervé 1997, Holloway 2004), and within the higher range of variation of earlier species including the very largest Homo erectus fossils and some Middle Pleistocene fossils (Grimaud-Hervé 1997). It is of course possible that the methods employed under-estimated Manot 1's endocranial volume, or that Manot 1 represents a small (perhaps female) individual for the population to which it belonged. Such a small endocranial volume is certainly unusual for Palaeolithic Homo sapiens, including the Skhul/Qafzeh samples, the Upper Palaeolithic Levantine Ohalo II fossil, and the Upper Palaeolithic specimens from Europe, which tend to have larger endocasts on average than recent populations (Henneberg 1995). It is not, however, smaller than what is known for small, recent Homo sapiens (eg Neubauer 2018). Considering the data available for hominin and Homo sapiens populations, it is not likely that the estimated volume of the Manot 1 specimen is representative of its population, and it should therefore not be interpreted in terms of trends in endocranial evolution. In agreement with the conclusions of Neubauer (2018), the rise in globularization noted between the early Levantine Homo sapiens from Qafzeh and Skhul and younger specimens $(\mathrm{AMH})$ is observed in Manot 1, whose endocranial shape is much more globular, characteristic of present-day humans. This shape feature does not seem to be related to higher encephalization considering the reduced cranial capacity of Manot 1 .

Although the estimated endocranial volume of Manot 1 falls on the lower end of the AMH spectrum, its morphological affinity with the different modern Homo sapiens groups is confirmed by the results of the 2D and 3D metrical analyses. 
Despite its small size, Manot 1's endocast falls within the variation of all three Homo sapiens groups for almost all the measurements carried out in this study (both in terms of uncorrected distances and for the adjusted z-scores). It falls outside of the Early Levantine Homo sapiens variation for only one measurement, the endocranial volume (moreover, the DOcE is only slightly different) and outside of the AMH variation for one measurement. This is expected, because some of these measurements do not allow for the classification of one individual fossil, as there is a large proportion of overlap in the variation of the different groups, each taxon differentiating itself from the others on a restrained number of variables. As expected, Manot 1 can safely be excluded from the Homo erectus, Neandertal and African Middle Pleistocene hominins groups. For the Homo sapiens groups, tendencies can be detected when inspecting several variables at a time using exploratory analyses (cf Figure 5,6,7) but Manot 1 does not cluster consistently with any specific group. For some aspects of cerebral organization / topology, Manot 1's endocast shows similarities more specifically with Upper Palaeolithic specimens from Central Europe such as the Predmost and Mladeč individuals. For example, Manot 1 differs from the earlier Levantine Homo sapiens (Qafzeh and Skhul) in manifesting considerable parietal bulging, a condition largely due to the presence of a well-developed supramarginal gyrus. This latter feature, in combination with its parallel lateral walls, lends the Manot 1 endocast its typically Homo sapiens pentagonal transversal outline in posterior view, with strong parietal eminence protruding on endocast as on calvaria observed in Manot 1 as on Predmost or Mladec specimens. This could argue the hypothesis of Hershkovitz et al. (2015) who conclude that the morphology of the Manot 1 calvaria suggests that it is not affiliated to the earlier Levantine groups of Homo sapiens from Skhul and Qafzeh. Although purely morphological data is insufficient to conclude with certainty on this hypothesis due to the 
large amounts of variation displayed by different groups of extant and archaeological Homo sapiens, the affinities of Manot 1's calvaria suggest closer ties to the later populations of Palaeolithic Europe. Overall, this calvaria has been shown to display a suite of features which are characteristic of Upper Palaeolithic European skulls as well as more generically "Homo sapiens" features and a few characters which can be encountered in Neandertals but that correspond to primitive traits that are shared by both species. On the other hand, the Manot 1 endocast fails to evidence any affinities with Neandertals. It does not bear any Neandertal-specific features and only falls within the limits of Neandertal variation for measurements which do not allow to discriminate Neandertals from Homo sapiens groups due to overlap in variation ranges. This is in agreement with the results of Herskhovitz et al. (Hershkovitz et al., 2015) obtained from the calvaria, and in keeping with attribution of the taxonomic position of Manot 1 as part of the Homo sapiens species.

Herskhovitz et al. (Hershkovitz et al., 2015) suggested that Manot 1 was displaying a supraniac fossa that would correspond to the Neandertal features. Thanks to the microCT data used here we could examinate the internal structure of the bone in this anatomical area. Previous work has allready identified some traits that are specific for the Neandertal suprainiac fossa. In Manot, the depression has some external features that slightly differ from the Neandertal classic shape in terms of extension and borders but more importantly it corresponds to a thinning of the external table. As a result, the depression observed in Manot is not a Neandertal trait.

Future discoveries of Levantine $\mathrm{AMH}$ remains dated from a similar period as Manot 1 will be crucial to the understanding of the affinities between the population represented by Manot 1, earlier Levantine populations, and Upper Palaeolithic European populations. 
More generally, although the endocranial features of Manot 1 seem to suggest some affinities to the UP populations of Western and Central Europe, it is not currently possible to clarify the nature of these affinities, due to the large amounts of variation displayed by $\mathrm{AMH}$ groups for the features present in the Manot 1 endocast, and to the overlap in their ranges of variation. 
Acknowledgments

The following individuals provided help during the research: Ofer Marder from Ben-

Gurion University and Omry Barzilai from the Israel Antiquities Authority for reading, discussing and commenting on this manuscript.

\section{Funding}

This work was supported by the Dan David Foundation, Binational Science Foundation (grant no. 2015303), Israel Science Foundation (grant no. 2632/18), The Leakey

Foundation, CARE Archaeological Foundation, Case Western Reserve University and Museum National d'Histoire Naturelle, Paris (Projet Transhumances).

\section{References}

Adams, D.C., Collyer, M., Kaliontzopoulou, A., Sherratt, E., 2016. geomorph: Software for geometric morphometric analyses.

Balzeau, A., Gilissen, E., Grimaud-Hervé, D., 2012. Shared pattern of endocranial shape asymmetries among great apes, anatomically modern humans, and fossil hominins. PLoS One. 7, e29581.

Balzeau, A., Grimaud-Hervé, D., Détroit, F., Holloway, R.L., Combès, B., Prima, S., 2013. First description of the Cro-Magnon 1 endocast and study of brain variation and evolution in anatomically modern Homo sapiens. Première description de l'endocrâne de Cro-Magnon 1 et étude de la variation et de l'évolution du cerveau chez les Hommes anatom. Bulletins et Mémoires de la Société d'Anthropologie de Paris. 25, 1-18. 
Balzeau, A, Rougier, H., 2010. Is the suprainiac fossa a Neandertal autapomorphy? A complementary external and internal investigation. J Hum Evol. 58: 1-22.

Balzeau, A., Rougier, H., 2013. New information on the modifications of the Neandertal suprainiac fossa during growth and development and on its etiology. Am. J. Phys. Anthropol. 151, 38-48.

Barzilai, O., Hershkovitz, I., Marder, O., 2016. The Early Upper Paleolithic Period at Manot Cave, Western Galilee, Israel. Human Evolution. 31, 85-100.

Barzilai, O., Hershkovitz, I., Marder, O., 2018. The Dan David Expedition to Manot Cave: 2010-2016 - An introduction tho the special issue. Journal of Human Evolution, submitted to special issue on Manot Cave.

Bruner, E., Mantini, S., Perna, A., Maffei, C., Manzi, G., 2005. Fractal dimension of the middle meningeal vessels: variation and evolution in Homo erectus, Neanderthals, and modern humans. European journal of morphology. 42, 217-224.

Bruner, E., Grimaud-Hervé, D., Wu, X., de la Cuétara, J.M., Holloway, R., 2015. A paleoneurological survey of Homo erectus endocranial metrics. Quaternary International. 368, 80-87.

Bruner, E., 2016. Human Paleoneurology. Springer, Series in Bio-Neuroinformatics.

Bruner, E., Ogihara, N., Tanabe, H.C., 2018. Digital endocasts. From skulls to brains. Springer.

Buck, L.T., Stringer, C.B., 2015. A rich locality in South Kensington: the fossil hominin collection of the Natural History Museum, London. Geological Journal. 50, 321-337.

Copes, L.E., Holloway, R.L., 2004. The Monte Circeo Neanderthal brain endocast. In: American Association of Physical Anthropology, 73rd Congress. Tampa, Florida, p. 
79.

de Lumley, H., 2016. La Grotte du Cavillon: sous la falaise des Baousse Rousse, Grimaldi, Vintimille, Italie. CNRS.

Dean, D., Hublin, J.-J., Holloway, R., Ziegler, R., 1998. On the phylogenetic position of the pre-Neandertal specimen from Reilingen, Germany. Journal of Human Evolution. $34,485-508$.

Falguères, C., Sémah, F., Saleki, H., Hameau, S., Tu, H., Féraud, G., Simanjuntak, H., Widianto, H., 2016. Geochronology of early human settlements in Java: What is at stake? Quaternary International. 416, 5-11.

Frouin, M., Guérin, G., Lahaye, C., Mercier, N., Huot, S., Aldeias, V., Bruxelles, L., Chiotti, L., Dibble, H.L., Goldberg, P., 2017a. New luminescence dating results based on polymineral fine grains from the Middle and Upper Palaeolithic site of La Ferrassie (Dordogne, SW France). Quaternary Geochronology. 39, 131-141.

Frouin, M., Lahaye, C., Valladas, H., Higham, T., Debénath, A., Delagnes, A., Mercier, N., 2017b. Dating the Middle Paleolithic deposits of La Quina Amont (Charente, France) using luminescence methods. Journal of Human Evolution. 109, 30-45.

Galaburda, A.M., 1995. Anatomic basis of cerebral dominance. In: J, D.R., K, H. (Eds.), Brain Asymmetry. MIT Press Cambridge, MA, pp. 51-73.

Grimaud-Hervé, D., 1997. L'évolution de l'encéphale chez Homo erectus et Homo sapiens. Les Cahiers de Paléoanthropologie. CNRS ed. Paris.

Grimaud-Hervé, D., 2004. Endocranial Vasculature. In: Holloway, R.L., C., B.D., M, Y. (Eds.), The Human Fossil Record: Brain Endocasts-The Paleoneurological Evidence, Volume 3. Wiley-Liss Inc., pp. 273-282. 
Grimaud-Hervé, D., 2005. Apports de quelques caractères morphologiques endocraniens dans la determination taxinomique des hominids de Jebel Ihroud (Maroc). Anthropologie. 43, 101-112.

Grimaud-Hervé, D., Lordkipanidze, D., 2010. The fossil hominid's brain of Dmanisi: D2280 and D2282. In: Yuan, M.S., Broadfield, D.C. (Eds.), The Human Brain Evolving: A Symposium in Honor of Professor Ralph L. Holloway. Indiana University, Bloomington, pp. 60-82.

Grün, R., Stringer, C.B., 1991. Electron spin resonance dating and the evolution of modern humans. Archaeometry. 33, 153-199.

Guérin, G., Frouin, M., Talamo, S., Aldeias, V., Bruxelles, L., Chiotti, L., Dibble, H.L., Goldberg, P., Hublin, J.-J., Jain, M., 2015. A multi-method luminescence dating of the Palaeolithic sequence of La Ferrassie based on new excavations adjacent to the La Ferrassie 1 and 2 skeletons. Journal of Archaeological Science. 58, 147-166.

Henry-Gambier, D., 2002. Les fossiles de Cro-Magnon (Les Eyzies-de-Tayac, Dordogne). Nouvelles données sur leur position chronologique et leur attribution culturelle. Bulletins et Mémoires de la Société d'Anthropologie de Paris. 14.

Hershkovitz, I., Marder, O., Ayalon, A., Bar-Matthews, M., Yasur, G., Boaretto, E., Caracuta, V., Alex, B., Frumkin, A., Goder-Goldberger, M., 2015. Levantine cranium from Manot Cave (Israel) foreshadows the first European modern humans. Nature. $520,216-219$.

Hershkovitz, I., Arensburg, B., 2017. Human Fossils from the Upper Palaeolithic through the Early Holocene. In: Enzel, Y., Bar-Yosef, O. (Eds.), Quaternary of the Levant: Environments, Climate Change, and Humans. Cambridge University Press, Cambridge, pp. 607-610. 
Hershkovitz, I., Latimer, B., Barzilai, O., Marder, O., 2017. Manot 1 calvaria and recent modern human evolution: an anthropological perspective. La calvaria de Manot 1 et l'évolution de l'Homme moderne: une perspective anthropologique. Bulletin et Mémoires de la Société d'Anthropologie de Paris. 29, 119-130.

Holloway, R.L., de La Coste-Lareymondie, M.C., 1982. Brain endocast asymmetry in pongids and hominids: some preliminary findings on the paleontology of cerebral dominance. American Journal of Physical Anthropology. 58, 101-110.

Holloway, R.L., Broadfield, D.C., Yuan, C., 2004. The Human Fossil Record: Brain Endocasts_-The Paleoneurological Evidence, Volume 3. Wiley-Liss, Inc.

Hyodo, M., Matsu'ura, S., Kamishima, Y., Kondo, M., Takeshita, Y., Kitaba, I., Danhara, T., Aziz, F., Kurniawan, I., Kumai, H., 2011. High-resolution record of the MatuyamaBrunhes transition constrains the age of Javanese Homo erectus in the Sangiran dome, Indonesia. Proceedings of the National Academy of Sciences. 108, 1956319568.

Indriati, E., Swisher III, C.C., Lepre, C., Quinn, R.L., Suriyanto, R.A., Hascaryo, A.T., Grün, R., Feibel, C.S., Pobiner, B.L., Aubert, M., 2011. The age of the 20 meter Solo River terrace, Java, Indonesia and the survival of Homo erectus in Asia. PloS one. 6, e21562.

Ingicco, T., de Vos, J., Huffman, O.F., 2014. The oldest gibbon fossil (Hylobatidae) from insular Southeast Asia: Evidence from Trinil,(East Java, Indonesia), Lower/Middle Pleistocene. PloS one. 9, e99531.

Joordens, J.C.A., d'Errico, F., Wesselingh, F.P., Munro, S., De Vos, J., Wallinga, J., Ankjærgaard, C., Reimann, T., Wijbrans, J.R., Kuiper, K.F., 2015. Homo erectus at Trinil on Java used shells for tool production and engraving. Nature. 518, 228. 
LeMay, M., 1999. Functional and anatomical asymmetries of the human brain. European journal of neurology. $6,79-85$.

Magori, C.C., Day, M.H., 1983. Laetoli Hominid 18: an early Homo sapiens skull. Journal of Human Evolution. 12, 747-753.

Manzi, G., Passarello, P., 1991. Anténéandertaliens et néandertaliens du Latium (Italie centrale). L'Anthropologie. 95, 501-522.

Marder, O., Barzilai, O., Abulafia, T., Hershkovitz, I., Goder-Goldberger, M., 2018. Chronocultural Considerations of Middle Paleolithic Occurrences at Manot Cave (Western Galilee), Israel. In: Akazawa, T., Nishiaki, Y. (Eds.), Replacement of Neanderthals by Modern Humans: Testing Evolutionary Models of Learning. Springer, Japan, pp. 49_ 63.

McDougall, I., Brown, F.H., Vasconcelos, P.M., Cohen, B.E., Thiede, D.S., Buchanan, M.J., 2012. New single crystal 40Ar/39Ar ages improve time scale for deposition of the Omo Group, Omo-Turkana Basin, East Africa. Journal of the Geological Society. $169,213-226$.

Mercier, N., Valladas, H., Bar-Yosef, O., Vandermeersch, B., Stringer, C., Joron, J.-L., 1993. Thermoluminescence date for the Mousterian burial site of Es-Skhul, Mt. Carmel. Journal of Archaeological Science. 20, 169-174.

Nadel, D., Grinberg, U., Boaretto, E., Werker, E., 2006. Wooden objects from Ohalo II (23,000 cal BP), Jordan Valley, Israel. Journal of Human Evolution. 50, 644-662.

Nespoulet, R., Chiotti, L., Henry-Gambier, D., 2013. Le Gravettien final de l'abri Pataud (Dordogne, France). British Archaeological Reports Series. 2458, 217.

Recheis, W., Macchiarelli, R., Seidler, H., Weaver, D.S., Schäfer, K., Bondioli, L., Weber, G.W., zur Nedden, D., 1999. Re-evaluation of the Endocranial Volume of the Guattari 
1 Neandertal Specimen (Monte Circeo). Collegium antropologicum. 23, 397-405.

Rendu, W., Beauval, C., Crevecoeur, I., Bayle, P., Balzeau, A., Bismuth, T., Bourguignon, L., Delfour, G., Faivre, J.-P., Lacrampe-Cuyaubère, F., 2014. Evidence supporting an intentional Neandertal burial at La Chapelle-aux-Saints. Proceedings of the National Academy of Sciences. 111, 81-86.

Richter, D., Grün, R., Joannes-Boyau, R., Steele, T.E., Amani, F., Rué, M., Fernandes, P., Raynal, J.-P., Geraads, D., Ben-Ncer, A., 2017. The age of the hominin fossils from Jebel Irhoud, Morocco, and the origins of the Middle Stone Age. Nature. 546, 293296.

Rougier, H., Semal, P., 2012. Spy Cave: 125 Years of Multidisciplinary Research at the Betche Aux Rotches (Jemeppe-sur-Sambre, Province of Namur, Belgium). Société royale belge d'Anthropologie et de Préhistoire.

Saban, R. 1984. Anatomie et évolution des veines ménngées chez les hommes fossiles. Paris, ENSB-CTSH Eds, 289p.

Saleki, H., 1997. Apport d'une intercomparaison de méthodes nucléaires (230TH/234U, ESR et $40 \mathrm{Ar} / 39 \mathrm{Ar}$ ) à la datation de couches fossilifères pléistocènes dans le dôme de Sangiran (Java, Indonésie). Ph.D. Dissertation, Muséum national d'histoire naturelle, Paris.

Schmitz, R.W., Serre, D., Bonani, G., Feine, S., Hillgruber, F., Krainitzki, H., Pääbo, S., Smith, F.H., 2002. The Neandertal type site revisited: interdisciplinary investigations of skeletal remains from the Neander Valley, Germany. Proceedings of the National Academy of Sciences. 99, 13342-13347.

Scolan, H., Santos, F., Tillier, A.-M., Maureille, B., Quintard, A., 2012. Des nouveaux vestiges néanderthaliens à Las Pélénos (Monsempron-Libos, Lot-et-Garonne, 
France) New neanderthal remains from Las Pélénos (Monsempron-Libos, Lot-etGaronne, France). Bulletins et Mémoires de la Société d'Anthropologie de Paris. 24, $69-95$.

Sémah, A.-M., Sémah, F., Djubiantono, T., Brasseur, B., 2010. Landscapes and Hominids' environments: changes between the Lower and the Early Middle Pleistocene in Java (Indonesia). Quaternary International. 223, 451-454.

Sémah, F., Sémah, A.-M., Simanjuntak, T., 2003. More than a million years of human occupation in insular Southeast Asia: the early archaeology of eastern and central Java. In: Mercader, J. (Ed.), Under the Canopy: The Archaeology of Tropical Rain Forests. Rutgers University Press, New Brunswick. Rutgers University Press, pp. $161-190$.

Shen, G., Gao, X., Gao, B., Granger, D.E., 2009. Age of Zhoukoudian Homo erectus determined with $26 \mathrm{Al} / 10 \mathrm{Be}$ burial dating. Nature. 458, 198-200.

Smith, G.E., 1907. On the asymmetry of the caudal poles of the cerebral hemispheres and its influence on the occipital bone. Anatomischer Anzeiger. 30, 574-578.

Smith, G.E., 1908. Right-handedness. The British Medical Journal. 596-598.

Smith, G.E., 1925. Right-and left-handedness in primitive men. British Medical Journal. 2, 1107-1110.

Stekelis, M., Yizraely, T., 1963. Excavations at Nahal Oren, preliminary report. Israel Exploration Journal. 13, 1-12.

Stout, D., Hecht, E., Khreisheh, N., Bradley, B., Chaminade, T., 2015. Cognitive demands of Lower Paleolithic toolmaking. PLoS One. 10, e0121804.

Stout, D., Toth, N., Schick, K., Chaminade, T., 2008. Neural correlates of Early Stone Age 
toolmaking: technology, language and cognition in human evolution. Philosophical

Transactions of the Royal Society of London B: Biological Sciences. 363, 19391949.

Svoboda, J., Klíma, B., Skrdla, P., 1995. The Gravettian project: activities during the 19911994 period. Archeologické rozhledy. 47, 279-300.

Svoboda, J., 2001. Analysis of the large hunter's settlements: excavation at Prědmostı in 1992. Archeologické rozhledy. 53, 431-443.

Swisher, C.C., Rink, W.J., Antón, S.C., Schwarcz, H.P., Curtis, G.H., Widiasmoro, A.S., 1996. Latest Homo erectus of Java: potential contemporaneity with Homo sapiens in Southeast Asia. Science. 274, 1870-1874.

Turq, A., Dibble, H.L., Goldberg, P., McPherron, S.P., Sandgathe, D., Mercier, N., Bruxelles, L., Laville, D., Madelaine, S., 2012. Reprise des fouilles dans la partie ouest du gisement de la Ferrassie, Savignac-de-Miremont, Dordogne: problématique et premiers résultats. In: Quaternaire Continental d'Aquitaine, Excursion, Livret Guide de Excursions. AFEQ-ASF, pp. 78-87.

Valladas, H., Mercier, N., Froget, L., Hovers, E., Joron, J.-L., Kimbel, W.H., Rak, Y., 1999. TL dates for the Neanderthal site of the Amud Cave, Israel. Journal of Archaeological Science. 26, 259-268.

Verna, C., 2006. Les restes humains moustériens de la Station Amont de la Quina(Charente, France): contexte archéologiqe et constitution de l'assemblage: étude morphologique et métrique des restes crânio-faciaux. Ph.D. Dissertation, Universite de Bordeaux.

Wild, E.M., Teschler-Nicola, M., Kutschera, W., Steier, P., Trinkaus, E., Wanek, W., 2005. Direct dating of Early Upper Palaeolithic human remains from Mladeč. Nature. 435, 
332-335.

Yokoyama, Y., Falgueres, C., De Lumley, M.-A., 1997. Datation directe d'un crâne ProtoCro-Magnon de Qafzeh par la spectrométrie gamma non destructive. Comptes rendus de l'Académie des sciences. Série 2. Sciences de la terre et des planètes. $324,773-779$.

Yokoyama, Y., Falguères, C., Sémah, F., Jacob, T., Grün, R., 2008. Gamma-ray spectrometric dating of late Homo erectus skulls from Ngandong and Sambungmacan, Central Java, Indonesia. Journal of Human Evolution. 55, 274-277.

Ziegler, R., Dean, D., 1998. Mammalian fauna and biostratigraphy of the pre-Neandertal site of Reilingen, Germany. Journal of Human Evolution. 34, 469-484. 


\section{Figure captions}

Figure 1. Endocast shape of Manot 1 in anterior (a), posterior (b), right lateral (c), left lateral (d), and superior (e) views.

Figure 2.

Figure 3. The location of the landmarks on Manot 1 endocast: Endocranial Euryon (1), Supramarginal lobule (2), Base of upper parietal gyrus (3), Middle of the upper parietal gyrus (4), Post-central sulcus (5), Temporo-cerebellar (6), Occipital pole (7), Endocranial Endinion (8), Perpendicular sulcus (9), Central sulcus (10), Middle of the frontal arc (11).

Figure 4. Endocast of Manot 1 in supero-antero-lateral view (top), supero-postero-lateral view (middle) and postero-lateral view (bottom). Vascular sinuses are marked in blue: Ss=Sagittal sinus, LTs=Left Transverse sinus, RTs=Right Transverse sinus, $\mathrm{Pa}=$ Pacchionian; Vessels are marked in red : MMS=Middle Meningeal System, $\mathrm{Bb}=$ Bregmatic branch, $\mathrm{Ob}=\mathrm{Obelic}$ branch, $\mathrm{L} b=$ Lambdatic branch; Cerebral reliefs are marked in yellow: Brc=Broca's area, $1 \mathrm{Fg}=$ Superior frontal gyrus, $2 \mathrm{Fg}=$ Middle frontal gyrus, Spg=Superior parietal gyrus, Smg=Supramarginal gyrus, Ang=Angular lobule, B=Base of lower parietal gyrus, $1 \mathrm{Tg}=$ Upper temporal Gyrus, 2Tg=Middle temporal gyrus, $3 \mathrm{Tg}=$ Inferior temporal gyrus, Op=Occipital pole, $\mathrm{Cr}=$ Cerebellum, Uc=Upper part of cerebellum, Lc=Lower part of cerebellum; Cerebral sulcus are marked in Green : PrCs=Pre-Central sulcus, Cs=Central sulcus, PoCs=Post-central sulcus, Inps=Intraparietal sulcus, Ls=Lateral sulcus, Sts=Superior temporal sulcus, MTs=Middle Temporal sulcus, TOs=TemporoOccipital sulcus, POs=Parieto-Occipital sulcus, Cirs=Circumferential Azyr sulcus; Bone landmarks are marked in orange: $\mathrm{Br}=\mathrm{Bregma}$, Cors=Coronal suture. 
Figure 5. Principal Component analysis (PC1-PC2) based on four measurements: WBFE= width at the base of the inferior frontal convolutions of the endocast; $\mathrm{HGQE}=$ height of endocast above the maximum length axis; $\mathrm{CPa}=$ Parietal sagittal chord; DOcE=projection of occipital lobes. Gray = Extant human; Blue $=\mathrm{AMH}$; Dark Green = African Middle Pleistocene hominins (Jebel Irhoud, Broken Hill, Laetoli H18); Pale Green = Early Levantine Homo sapiens (Skhul/Qafzeh); Red = Neandertals, Orange $=$ Homo erectus, Purple $=$ Manot 1.Figure 7. Principal Component analysis (PC1-PC3) based on four measurements: WBFE= width at the base of the inferior frontal convolutions of the endocast; HGQE=height of endocast above the maximum length axis; CPa=Parietal sagittal chord; DOcE=projection of occipital lobes. Gray = Extant humans; Blue = AMH; Dark Green $=$ African Middle Pleistocene hominins (Jebel Irhoud, Broken Hill, Laetoli H18); Pale Green = Early Levantine Homo sapiens (Skhul/Qafzeh)); Red = Neanderthals, Orange $=$ Homo erectus, Purple $=$ Manot 1.

Figure 6. Left - Principal Component analysis of endocast shape. Gray = Extant human; Blue $=\mathrm{AMH} ;$ Dark Green = African Middle Pleistocene hominins (Jebel Irhoud, Broken Hill, Laetoli H18); Pale Green = Early Levantine Homo sapiens $($ Skhul/Qafzeh $) ;$ Red $=$ Neandertals, Orange $=$ Homo erectus, Purple $=$ Manot 1.

Right - Deformation plots for PC1, PC2 and PC3. The plots describe the movements (direction and magnitude) of each of the 11 landmarks along the axes. Note that only the landmarks situated along the midsagittal plane (point 7 included) are connected by lines to create the lateral profile of the endocast. Endocranial Euryon (1), Supramarginal lobule (2), Base of the superior parietal gyrus (3), Middle of the superior parietal gyrus (4), Post-central sulcus (5), Temporo- 
cerebellar (6), Occipital pole (7), Endocranial Endinion (8), Perpendicular sulcus (9), Central sulcus (10), Middle of the frontal arc (11).

\subsubsection{Bivariate analysis}

Two bivariate scatterplots, one showing CPa against WBFE (Figure 4) and the other CPa against DOcE (Figure 5), are provided. In both scatterplots, Manot 1 falls within the variation range of all 3 groups of Homo sapiens (early Levantine Homo sapiens, AMH and extant humans) and outside of the other groups considered, suggesting an expansion of the parietal lobes relative to the other cerebral lobes. The width between the pars opercularis of both inferior frontal gyri increases from Homo erectus to Homo sapiens, showing a large range of variation for this latter group, in which Manot 1 is located. Figure 5 indicates that the posterior extension of Manot 1's occipital lobes is similar to Homo erectus and Homo sapiens, and is different from Neandertals because of their marked occipital projection. The latter is associated with the strong occipital bulging of the occipital bone (bunning), considered as an autapomorphy of this hominin group (Hublin, 1978; Trinkaus and LeMay, 1982; Smith and Trinkaus, 1991; Gunz and Harvati, 2007). Biplots of these variables combinations show the increasing of the sagittal parietal chord associated to the frontal and parietal increasing of the widths. The ratio of parietal chord to occipital chord (Table 5) in Manot 1 is 1.47 . This value suggests an elongated chord of the parietal lobe (index $>1$ ), which falls within the variation for early Levantine Homo sapiens (mean=1.3) and extant humans (mean=1.3), and close to the upper limit of the Upper Palaeolithic group (mean=1.2). It is much higher than the values calculated for the Neandertals (mean=0.94) and Homo erectus (mean=0.85), two hominin groups where the occipital chord is longer than the parietal 
chord. The two sagittal chords, parietal and occipital, are nearly equivalent in length in African Middle Pleistocene hominins (mean=1.03). The differences in this chord ratio between modern Homo sapiens and Neandertals (and most early hominins) are mainly due to the considerable antero-posterior extension of the parietal lobes in the former group (Grimaud-Hervé, 1997), a sagittal extension which is noticeable on Manot 1. 